\title{
Lamellar Architecture Affords Salt Cocrystals with
}

\section{Tunable Stoichiometry}

\author{
Michael K. Bellas, Lake V. MacKenzie, and Adam J. Matzger
}

Department of Chemistry, Macromolecular Science and Engineering Program, University of Michigan, 930 N. University Avenue, Ann Arbor, Michigan 48109-1055, United States

\section{Electronic Supporting Information}

\section{Table of Contents}

SI 1. Experimental

SI 2. Table of Crystallographic Data

SI 3. Thermal Ellipsoid Plots

SI 4. Raman Spectra

SI 5. PXRD Patterns

SI 6. Thermal Analysis

SI 7. Dynamic Vapor Sorption

SI 8. Controlled Humidity Cell Microscopy

SI 9. Morphology

SI 10. CSD Search

SI 11. Computations

SI 12. References 


\section{SI 1. Experimental}

Ammonium hexafluorophosphate (AH) was obtained from MilliporeSigma (98\%). Pyrazinamide (PZA) was obtained from Acros Organics (99\%). Ethanol (EtOH) mas obtained from Decon Laboratories. 2-propanol (i-PrOH), acetonitrile $(\mathrm{MeCN})$, isooctane, methanol $(\mathrm{MeOH})$, and hexanes were obtained from Fisher Scientific (ACS certified grade) and stored over $4 \AA$ molecular sieves ( $3 \AA$ in the case of $\mathrm{MeOH}$ ) prior to use. Diethyl ether (ether) was obtained from MilliporeSigma, passed through an activated alumina column, and stored over $4 \AA$ molecular sieves prior to use. Disposable syringe filters were obtained from Macherey Nagel $(0.45 \mu \mathrm{m}$, polytetrafluoroethylene).

\section{Synthesis}

Note: Some of these materials undergo solvent, heat, and mechanical energy induced phase changes; as such, isolation and characterization procedures must be carefully conducted to prevent phase conversion and/or phase contamination. See table S1 below.

Table S1. Phase conversions of the AH-PZA cocrystals

\begin{tabular}{|c|c|c|c|}
\hline Cocrystal & Heat & $\mathrm{H}_{2} \mathrm{O}$ & Mechanical Energy \\
\hline $1 \mathrm{AH}: 3 \mathrm{PZA}$ & 1AH:1PZA(II) \& PZA & 1AH:1PZA(II) \& PZA & 1AH:1PZA(II) \& PZA \\
\hline 1AH:1PZA & 1AH:1PZA(II) & 1AH:1PZA(II) & 1AH:1PZA(II) \\
\hline 3AH:2PZA & $\mathrm{AH}^{*}$ & 1AH:1PZA(II) \& AH & 1AH:1PZA(II) \& AH \\
\hline 1AH:1PZA(II) & none & none & none \\
\hline
\end{tabular}

*PZA sublimes without recrystallizing on the crystal surface; in contrast to the $1 \mathrm{AH}: 3 \mathrm{PZA} \rightarrow$ 1AH:1PZA(II) + PZA heated conversion in which PZA does crystallize on the 1AH:1 PZA(II) crystal surface prior to sublimation.

\section{Preparation of cosaturated and saturated solutions}

Solid AH and/or PZA were added (sequentially) to $20 \mathrm{~mL}$ vials containing $10 \mathrm{~mL}$ of the desired solvent until solid material persisted. The vials were then sealed and placed on an orbital shaker for $12 \mathrm{~h}$. If after $12 \mathrm{~h}$ solid $\mathrm{AH}$ and/or PZA do not persist additional solid AH and/or PZA is added and the process repeated. Solutions are not stored in excess of $96 \mathrm{~h}$.

1AH:1PZA(II) by liquid assisted grinding (LAG)

PZA (20.0 $\mathrm{mg}, 0.162 \mathrm{mmol})$ and AH $(26.4 \mathrm{mg}, 0.162 \mathrm{mmol})$ were combined in a mortar and ground for 20 minutes with 4-5 drops of $\mathrm{MeCN}$ added via syringe over the course of grinding.

1AH:1PZA(II) by slurry conversion

PZA (20.0 mg, $0.162 \mathrm{mmol})$ and AH $(26.4 \mathrm{mg}, 0.162 \mathrm{mmol})$ were combined in a $4 \mathrm{~mL}$ vial. Cosaturated $\mathrm{H}_{2} \mathrm{O}(1 \mathrm{~mL})$ was then added via syringe filter. The vial was sealed and placed on an 
orbital shaker for 5 days. Water $(100 \mu \mathrm{L})$ was then added to the vial, the solids collected via vacuum filtration, and rinsed with ether $(3 \times 3 \mathrm{~mL})$.

\section{AH:1PZA(II) from solution}

Cosaturated $\mathrm{H}_{2} \mathrm{O}(2 \mathrm{~mL})$ was added to a $4 \mathrm{~mL}$ vial via syringe filter. The vial was sealed and placed in a refrigerator $\left(7.5^{\circ} \mathrm{C}\right)$ for $12 \mathrm{~h}$. At this time if no crystals are present (rare occurrence) slightly agitating the vial and returning to the refrigerator for $1 \mathrm{~h}$ induces crystallization. Water $(100 \mu \mathrm{L})$ was then added to the vial, the solids collected via vacuum filtration, and rinsed with ether $(3 \times 3 \mathrm{~mL})$.

\section{$1 A H: 3 P Z A$}

PZA (20.0 mg, $0.162 \mathrm{mmol})$ and AH $(26.4 \mathrm{mg}, 0.162 \mathrm{mmol})$ were combined in a $4 \mathrm{~mL}$ vial to which cosaturated i-PrOH $(2 \mathrm{~mL})$ was via syringe filter. The vial was sealed and placed in a refrigerator $\left(7.5^{\circ} \mathrm{C}\right)$ for $12 \mathrm{~h}$. i-PrOH $(100 \mu \mathrm{L})$ was added to the vial, the solids collected via vacuum filtration, and rinsed with ether $(3 \times 3 \mathrm{~mL})$.

\section{AH:1PZA}

PZA (57.4 mg, $0.466 \mathrm{mmol})$ and AH $(76.0 \mathrm{mg}, 0.466 \mathrm{mmol})$ were combined in a constant pressure addition funnel fitted with a Teflon stopcock, glass wool filter, and $10 \mathrm{~mL}$ conical flask (apparatus shown below in figure $\mathrm{S} 1)$. Cosaturated $\mathrm{EtOH}(4 \mathrm{~mL})$ was added via syringe filter. The apparatus was sealed with a greased glass stopper. The apparatus was thoroughly heated using a heat gun until solids dissolved. Caution is required here as you are creating pressure while heating this sealed system. Ensure the pressure equalizing channel does not condense solvent into the conical flask. After the solids are dissolved the stopcock was opened and the solution filtered. The stopcock was then closed and the solution allowed to cool/rest at ambient for $16 \mathrm{~h}$. The conical flask was then removed, PZA saturated i-PrOH $(3 \mathrm{~mL})$ was added to the flask, the solids collected via vacuum filtration, and immediately rinsed with chilled $\left(-80^{\circ} \mathrm{C}\right)$ i-PrOH $(1 \times 2 \mathrm{~mL})$ followed by chilled $\left(-80^{\circ} \mathrm{C}\right)$ isooctane $(1 \times 6 \mathrm{~mL})$.

\section{AH:2PZA}

PZA (20.7 mg, $0.168 \mathrm{mmol})$ and AH (274 $\mathrm{mg}, 1.68 \mathrm{mmol})$ were combined in a constant pressure addition funnel fitted with a Teflon stopcock, glass wool filter, and $10 \mathrm{~mL}$ conical flask (apparatus shown below in figure $\mathrm{S} 1)$. Cosaturated i-PrOH $(4 \mathrm{~mL})$ was then added via syringe filter. The mixture is heated and filtered as in the preparation of 1AH:1PZA given above. After a brief time (2-3 minutes), the conical flask was then removed, fitted with a glass stopper, transferred to a preheated $\left(80^{\circ} \mathrm{C}\right)$ sand bath, and allowed freely cool to ambient. PZA saturated $\mathrm{MeOH}(300 \mu \mathrm{L})$ was added to the flask, the solids collected via vacuum filtration, and immediately rinsed with chilled $\left(-80^{\circ} \mathrm{C}\right)$ i-PrOH $(1.5 \mathrm{~mL})$ followed by chilled $\left(-80^{\circ} \mathrm{C}\right)$ isooctane $(1 \times 6 \mathrm{~mL})$. This results in a physical mixture of $\mathbf{3 A H}: 2 \mathbf{P Z A}$ and $\mathrm{AH}$ which was carefully separated with the aid of crystal manipulation micro tools under a microscope. 


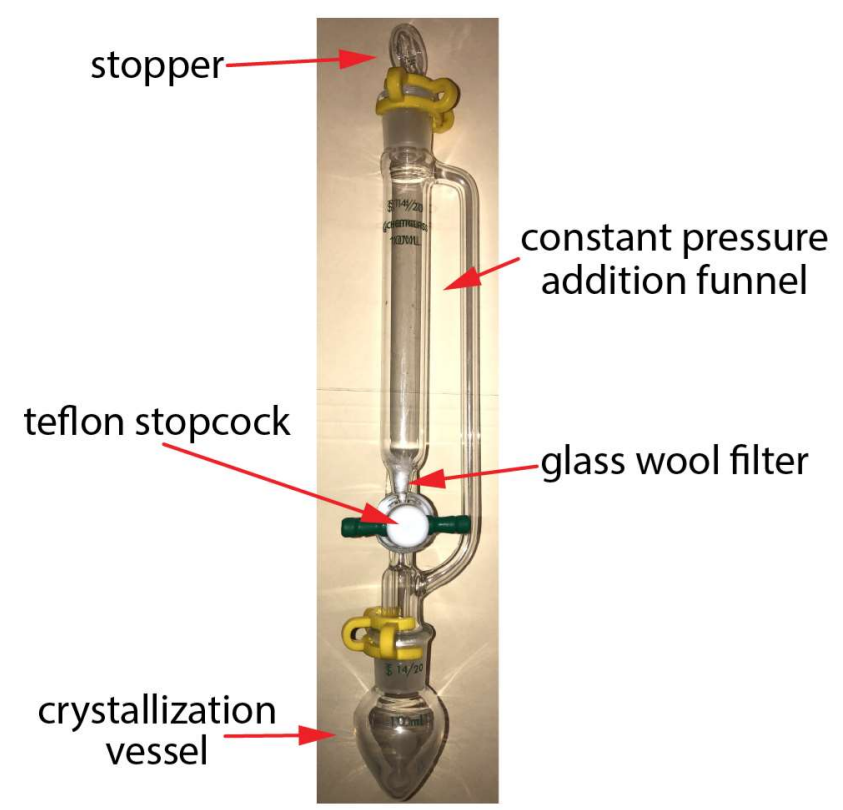

Figure S1. Crystallization apparatus

\section{Characterization}

General methods are described here; deviations will be noted as necessary.

\section{Single-Crystal X-Ray Structure Determination}

Single-crystal X-ray diffraction data were collected using a Rigaku XtaLAB Synergy-S X-ray diffractometer in a kappa goniometer geometry configuration; an Oxford Cryostream 800 low temperature device is also equipped. The $\mathrm{X}$-ray source is a PhotonJet-S microfocus $\mathrm{Cu}$ source $(\lambda$ $=1.54187 \AA$ ) operated at $50 \mathrm{kV}$ and $1 \mathrm{~mA}$. X-ray intensities were measured with a HyPix-6000HE detector held $34.00 \mathrm{~mm}$ from the sample. The data were processed using CrysAlisPro v38.46 (Rigaku Oxford Diffraction) and were absorption corrected. The structures were determined using $\mathrm{OLEX}^{[1]}$ as well as SHELXT ${ }^{[2]}$ and refined with SHELXL. ${ }^{[3]}$ All non-hydrogen atoms were refined anisotropically with hydrogen atoms placed at idealized positions.

\section{Powder X-Ray Diffraction}

All powder pattern data were collected using a Panalytical Empyrean system utilizing $\mathrm{Cu}-\mathrm{K} \alpha$ radiation $(\lambda=1.54187 \AA)$ and operating at $45 \mathrm{kV}$ and $40 \mathrm{~mA}$. The system uses a Bragg-Brentano HD X-ray optic and an X'Celerator Scientific detector operating in a continuous 1D scan mode. Scans were conducted according to the following parameters: $2 \theta=3^{\circ}$ to $50^{\circ}$, step size $=0.008^{\circ}$, and step speed $=100$ seconds. The data were worked up using Origin 2017. 


\section{Raman Spectroscopy}

Raman spectra were collected using a Renishaw inVia Raman Microscope equipped with a Leica microscope and the following configurations: 1) a $633 \mathrm{~nm}$ laser, 1800 lines $/ \mathrm{mm}$ gratings, $50 \mu \mathrm{m}$ slit size, and a RenCam CCD detector; where spectra were collected in static scan mode centered on $3200 \mathrm{~cm}^{-1}$ for 16 accumulations. 2) a $785 \mathrm{~nm}$ laser, 1200 lines $/ \mathrm{mm}$ gratings, $65 \mu \mathrm{m}$ slit size, and a RenCam CCD detector; where spectra were collected in extended scan mode with a range of $3600-400 \mathrm{~cm}^{-1}$. All spectra were analyzed using the WiRE 3.4 software package (Renishaw). Calibration was performed using a silicon standard in static mode.

\section{Dynamic Vapor Sorption (DVS)}

Dynamic vapor sorption (DVS) experiments were performed using a Q5000 SA Dynamic Vapor Sorption Analyzer. Sample mass was monitored from 0-96\% RH at steps of 2\% RH allowing 1200 minutes for equilibration and conducted in triplicate.

\section{Differential Scanning Calorimetry (DSC)}

Differential scanning calorimetry (DSC) thermograms were recorded on a TA Instruments Q10 DSC. All experiments were carried out at a heating rate of $5^{\circ} \mathrm{C} / \mathrm{min}$, covering a temperature range of $30{ }^{\circ} \mathrm{C}$ to $475{ }^{\circ} \mathrm{C}$. Samples were analyzed in Tzero ${ }^{\mathrm{TM}}$ hermetic aluminum DSC pans. The instrument was calibrated using an indium standard and all DSC thermograms were analyzed using TA Universal Analysis 2000, V4.5A, build 4.5.0.5.

\section{Thermogravimetric Analysis (TGA)}

Thermogravimetric analysis (TGA) thermograms for each sample were recorded on a TA Instruments Q50 TGA. All experiments were conducted on platinum TGA sample pans under a nitrogen purge of $50 \mathrm{~mL} / \mathrm{min}$ with a heating rate of $5{ }^{\circ} \mathrm{C} / \mathrm{min}$, covering a temperature range of 27 ${ }^{\circ} \mathrm{C}$ to $475^{\circ} \mathrm{C}$. The instrument was calibrated using the Curie points of alumel and nickel standards and all TGA thermograms were analyzed using TA Universal Analysis 2000, V4.5A, build 4.5.0.5.

\section{Hot stage microscopy}

Hot stage microscopy experiments were conducted using a Linkam LTS420 hot stage with a TS96 controller and the LINK software package. Microscopy and image capture conducted using a Nikon Eclipse E600 research microscope outfitted with a FLIR Grasshopper 3 camera system.

\section{Controlled Humidity Cell Microscopy}

Controlled Humidity Cell Microscopy experiments were conducted using a Linkam LTS420 hot stage with an RH95 Humidity Controller connected to an LNP96-S controller and the LINK software package. Microscopy and image capture conducted using a Nikon Eclipse E600 research microscope outfitted with a FLIR Grasshopper 3 camera system.

\section{Image capture}

Images of crystal populations illustrating morphology were captured using a Hirox RH-2000 digital microscope. 
SI 2. Crystallographic Data

Table S2. Crystal structure data

\begin{tabular}{c|cccc}
\hline $\begin{array}{c}\text { Temperature } \\
\text { ambient }\end{array}$ & 1AH:3PZA & 1AH:1PZA & 3AH:2PZA & 1AH:1PZA(II) \\
\hline Space Group & $P 2_{1} / n$ & $P-1$ & $P-1$ & $P-1$ \\
a $(\AA)$ & $7.59408(12)$ & $5.4158(2)$ & $5.45126(15)$ & $6.1557(2)$ \\
$\mathrm{b}(\AA)$ & $29.4596(4)$ & $5.6733(2)$ & $5.66953(16)$ & $8.3366(3)$ \\
$\mathrm{c}(\AA)$ & $10.26393(10)$ & $17.8210(8)$ & $21.6490(6)$ & $11.0525(4)$ \\
$\alpha\left({ }^{\circ}\right)$ & 90 & $87.585(2)$ & $95.357(2)$ & $75.820(3)$ \\
$\beta\left(\left(^{\circ}\right)\right.$ & $104.4926(16)$ & $81.922(3)$ & $90.741(2)$ & $83.209(3)$ \\
$\gamma\left({ }^{\circ}\right)$ & 90 & $89.982(3)$ & $90.021(2)$ & $85.869(3)$ \\
Volume $\left(\AA^{3}\right)$ & $2223.16(6)$ & $541.64(4)$ & $666.11(3)$ & $545.50(3)$ \\
$R_{1}(\%)$ & 4.65 & 6.62 & 7.61 & 6.47 \\
$R_{\text {int }}(\%)$ & 3.25 & 2.57 & 3.59 & 2.24 \\
$\rho_{\text {calc }}\left(\mathrm{g} \mathrm{cm}{ }^{-3}\right)$ & 1.591 & 1.754 & 1.833 & 1.742 \\
Deposition & 2071180 & 2071179 & 2071182 & 2071181 \\
number & & & &
\end{tabular}


SI 3. Thermal Ellipsoid Plots

\section{AH:3PZA}

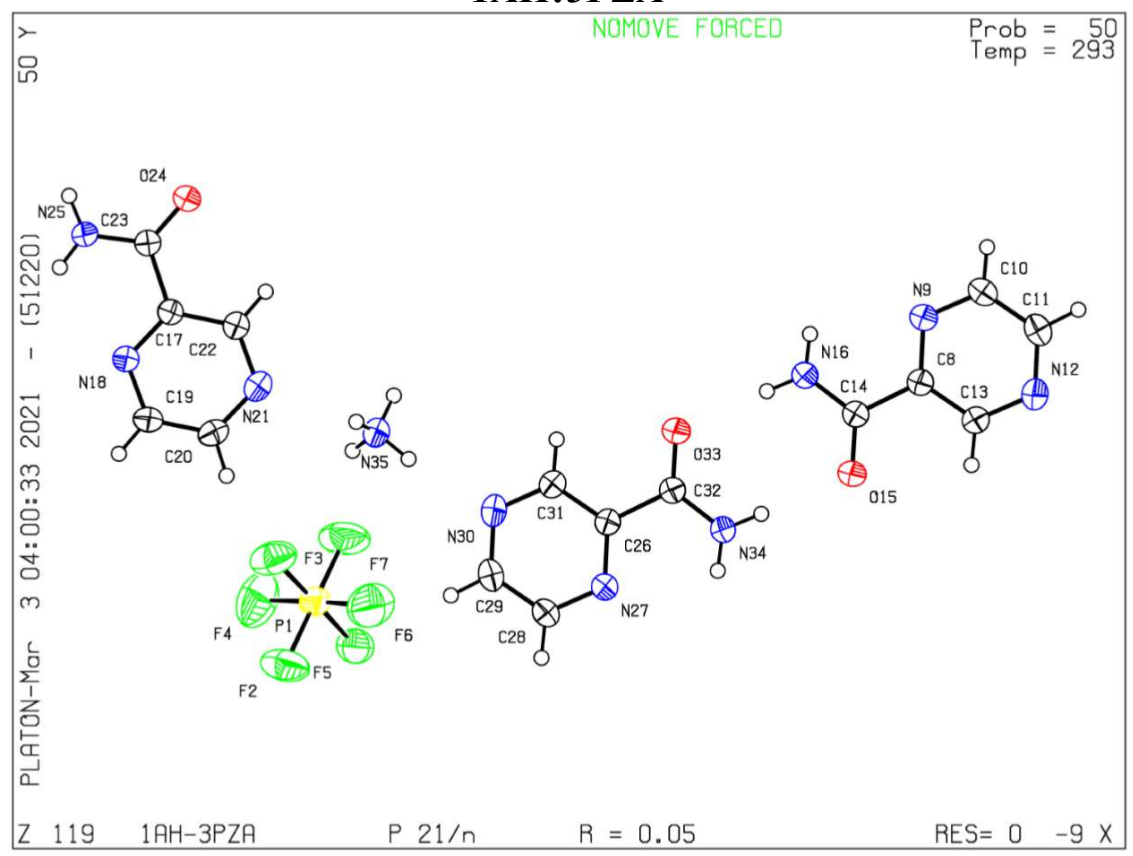

Figure S2. Thermal Ellipsoid Plot of 1AH:3PZA

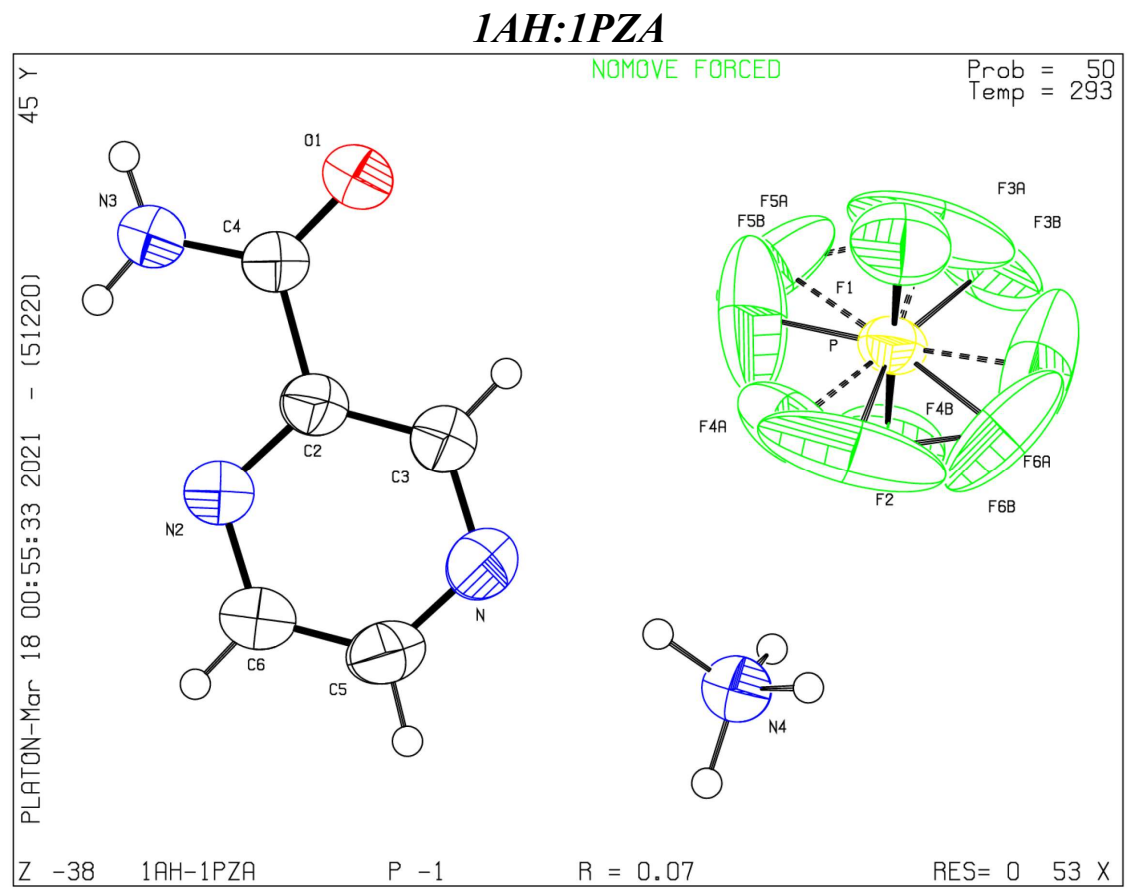

Figure S3. Thermal Ellipsoid Plot of 1AH:1PZA 
3AH:2PZA

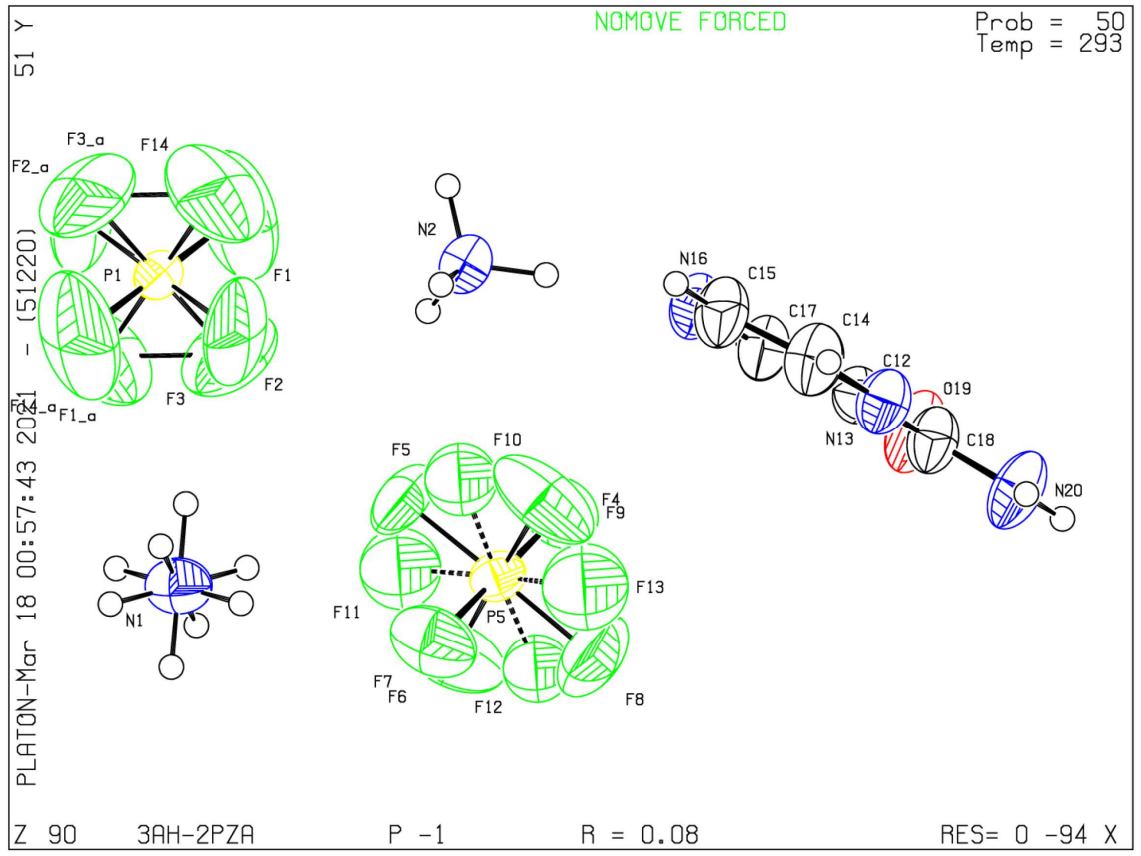

Figure S4. Thermal Ellipsoid Plot of 3AH:2PZA

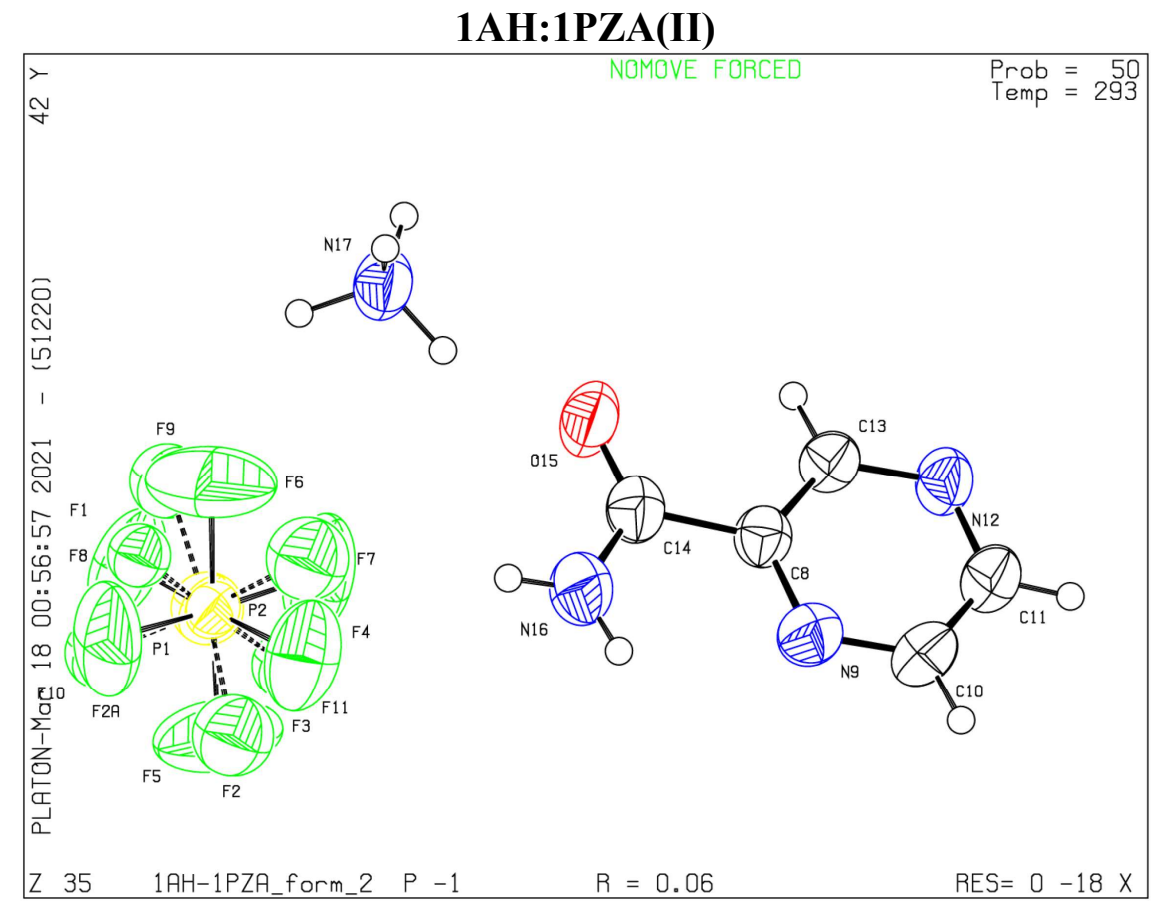

Figure S5. Thermal Ellipsoid Plot of 1AH:1PZA(II) 


\section{SI 4. Raman Spectra}

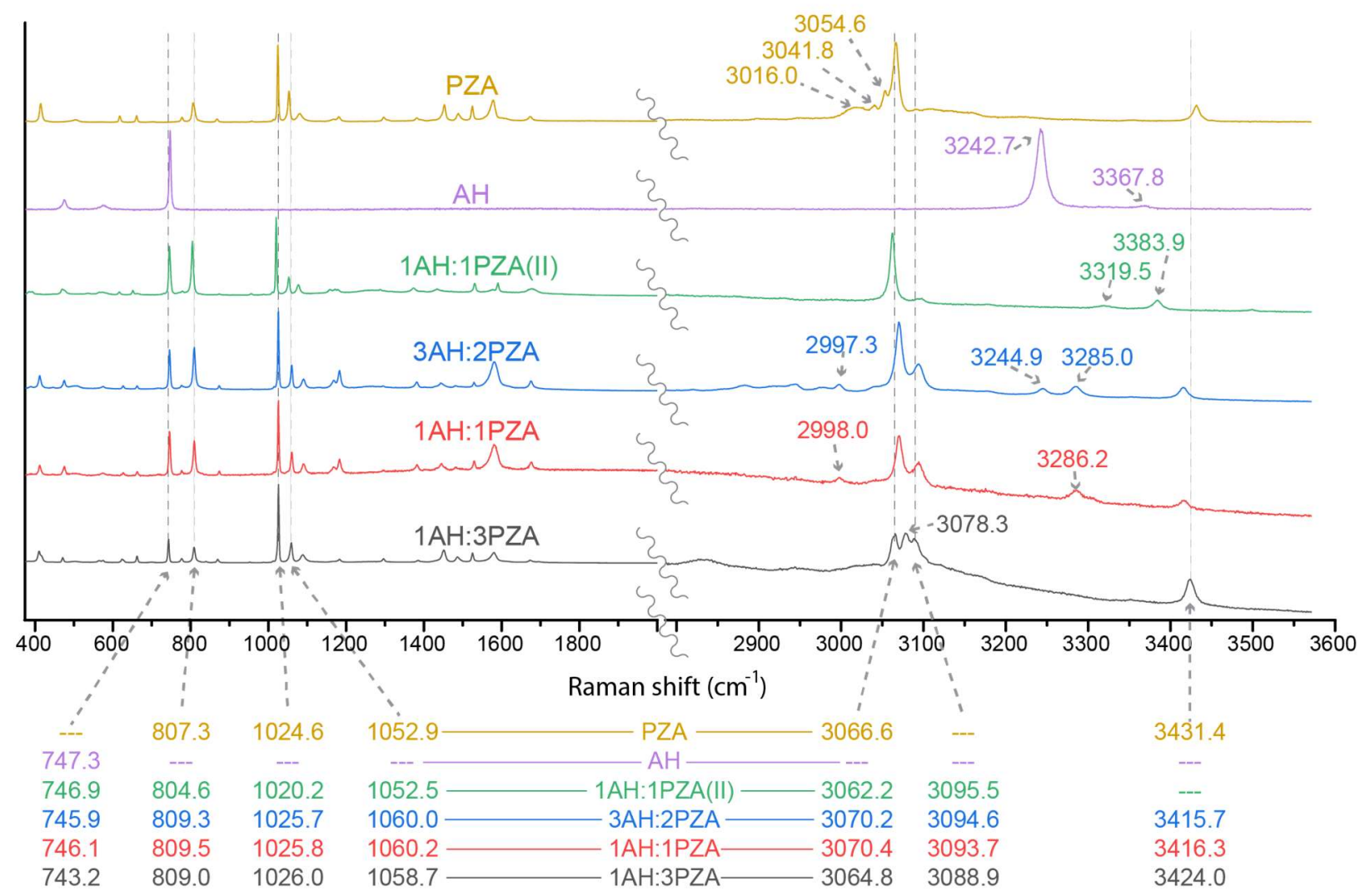

Figure S6. Raman spectra of $\alpha$-PZA (PZA), AH, 1AH:1PZA(II), 3AH:2PZA, 1AH:1PZA, and 1AH:3PZA. 375-2000 wavenumber spectra collected using an excitation wavelength of $785 \mathrm{~nm}$. 2786-3571 wavenumber spectra collected using an excitation wavelength of $633 \mathrm{~nm}$. 


\section{SI 5. PXRD diffraction patterns}

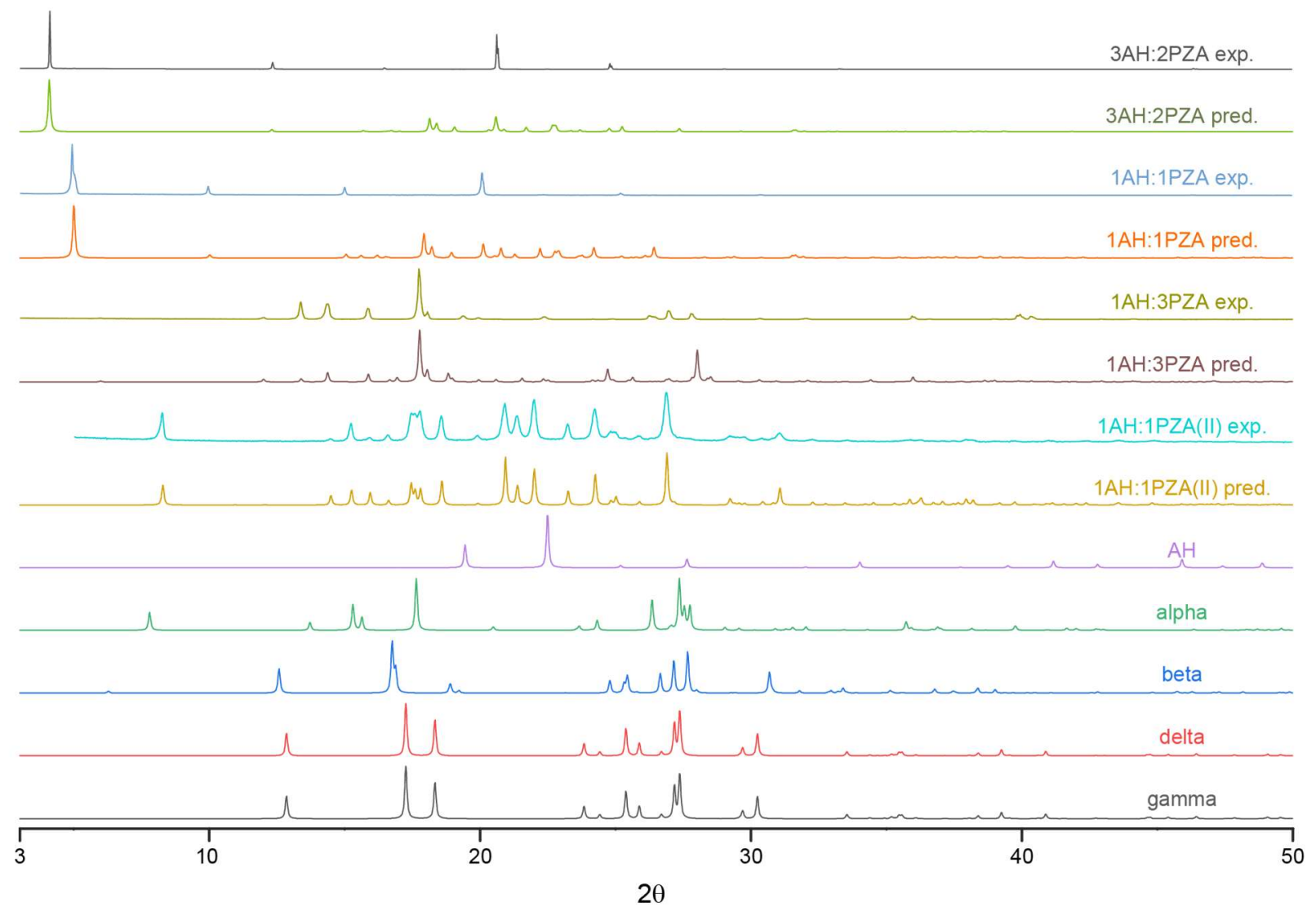

Figure S7. Experimental (exp.) and predicted (pred.) PXRD data for all AH-PZA cocrystals as well as predicted PXRD data for AH and all known PZA polymorphs (labeled as alpha, beta, delta, and gamma). 


\section{SI 6. Thermal analysis}

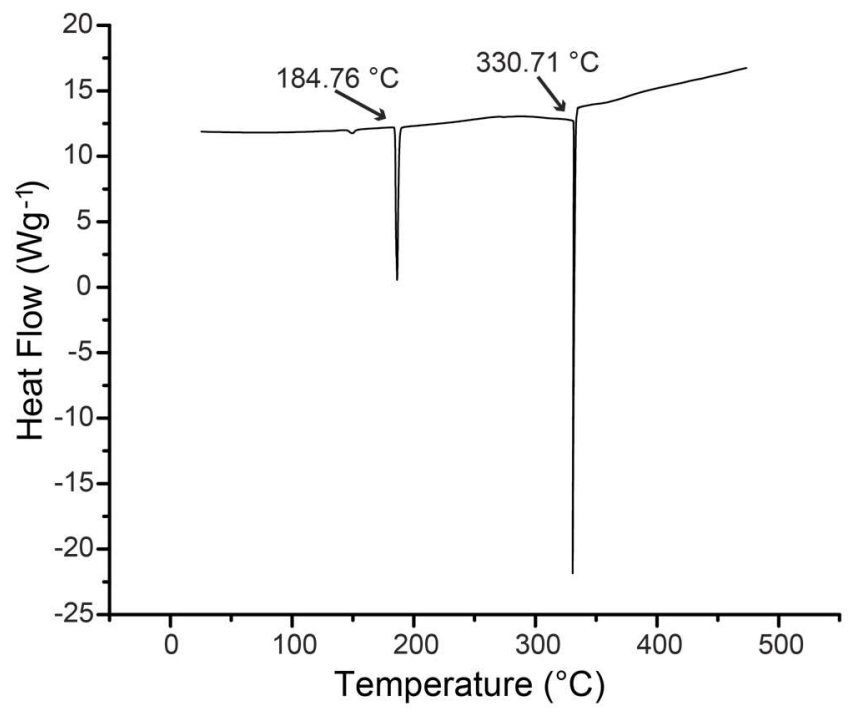

Figure S8. DSC thermogram of PZA (alpha)

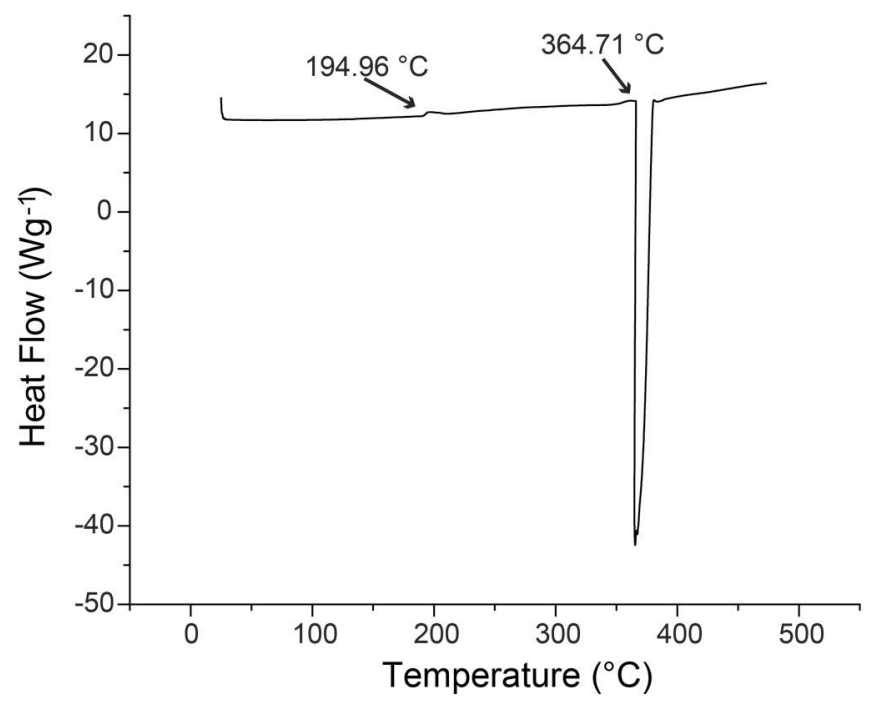

Figure S9. DSC thermogram of AH 


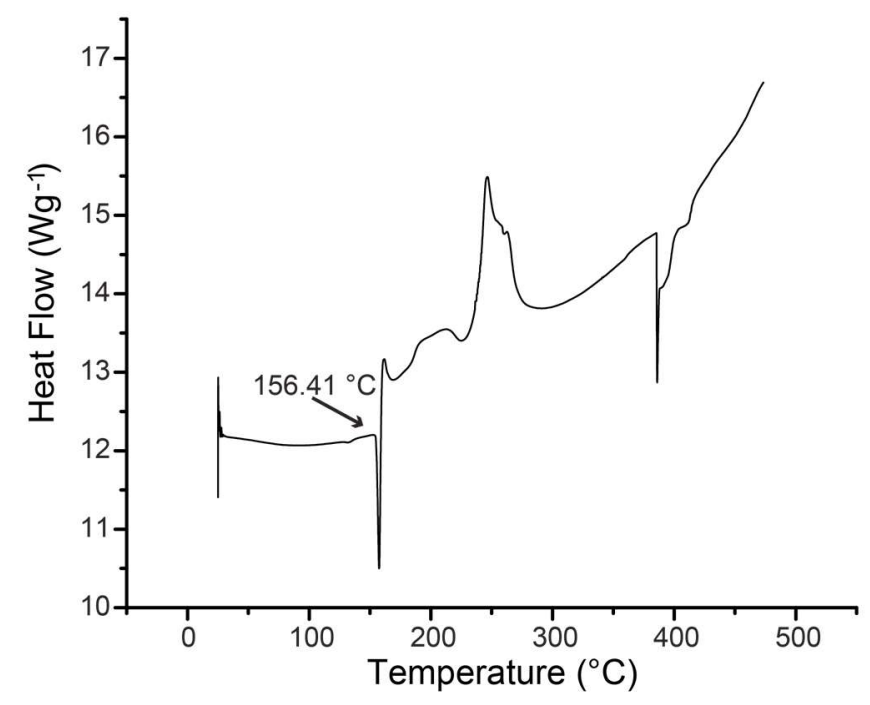

Figure S10. DSC thermogram of 1AH:1PZA(II)

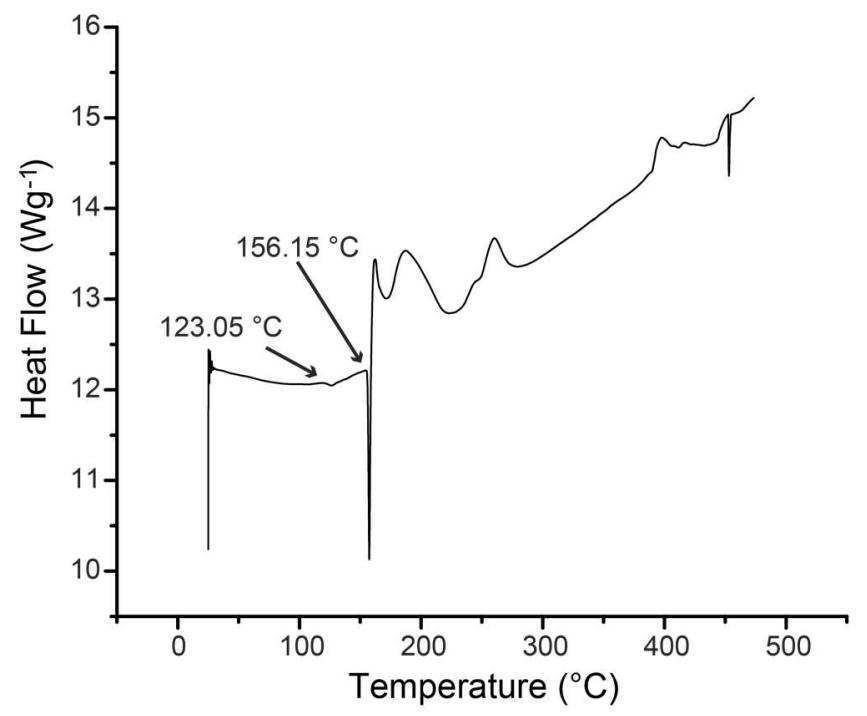

Figure S11. DSC thermogram of 1AH:3PZA 

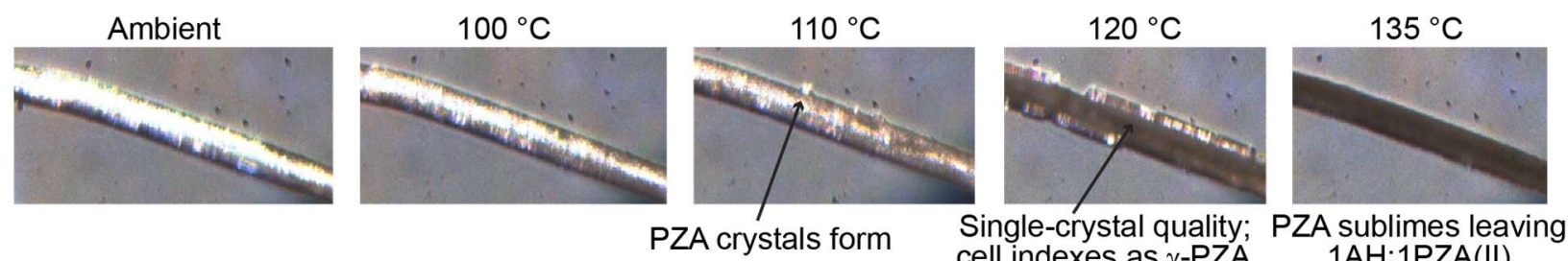

PZA crystals form

Single-crystal quality; cell indexes as $\gamma$-PZA $1 \mathrm{AH}: 1 \mathrm{PZA}(\mathrm{II})$

Figure S12. Hot stage microscopy images of 1AH:3PZA. $1{ }^{\circ} \mathrm{C} / \mathrm{min} . \rightarrow 135^{\circ} \mathrm{C}$ from ambient, 10 min hold.

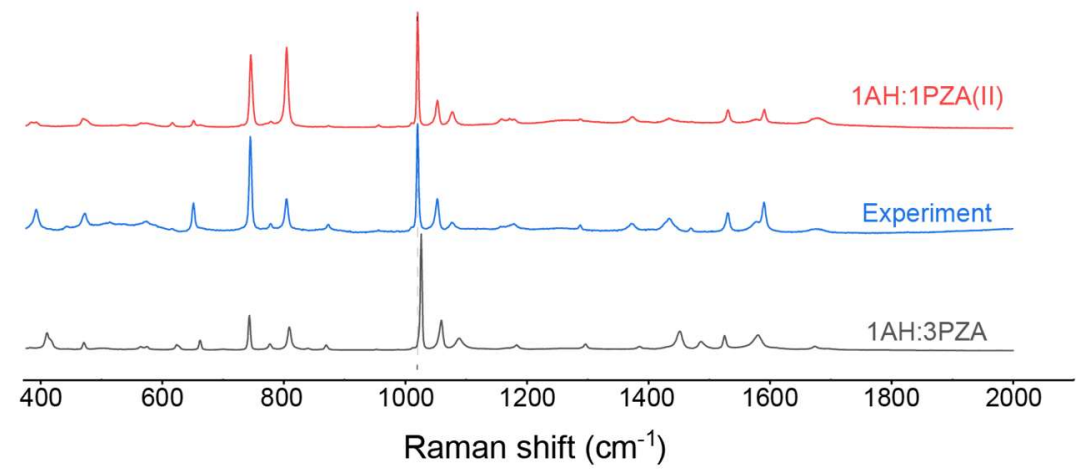

Figure S13. Raman spectra of 1AH:3PZA, the results of a DSC experiment where 1AH:3PZA was heated $1{ }^{\circ} \mathrm{C} / \mathrm{min} . \rightarrow 140{ }^{\circ} \mathrm{C}$ from ambient), and 1AH:1PZA(II). This phase change occurs with the loss of PZA as shown in Figure S12.

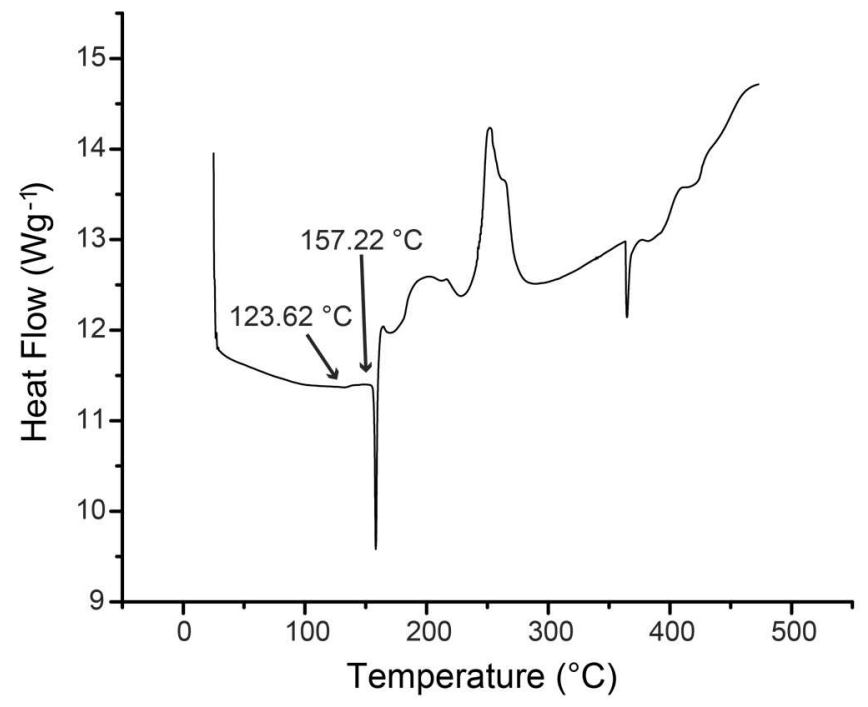

Figure S14. DSC thermogram of 1AH:1PZA 

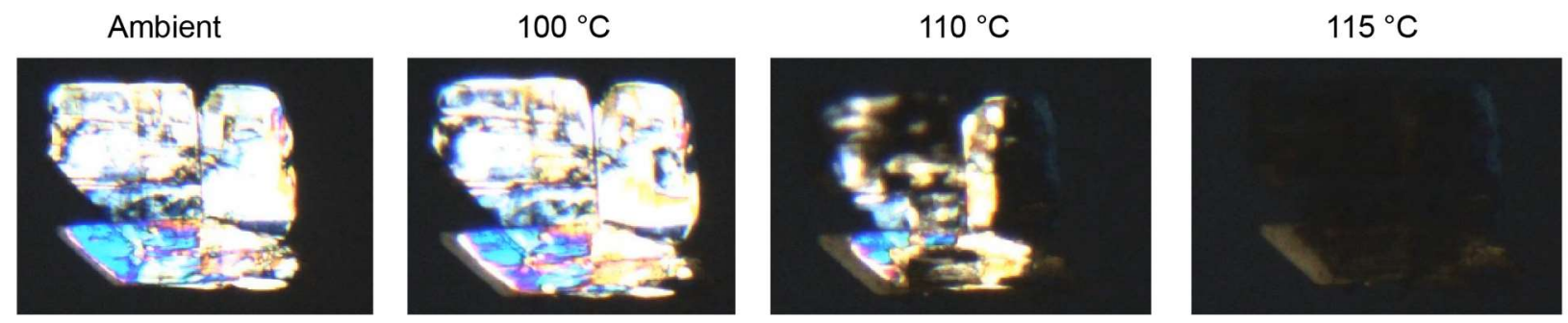

Figure S15. Hot stage microscopy images of 1AH:1PZA. $1{ }^{\circ} \mathrm{C} / \mathrm{min} . \rightarrow 130^{\circ} \mathrm{C}$ from ambient, 10 min hold.

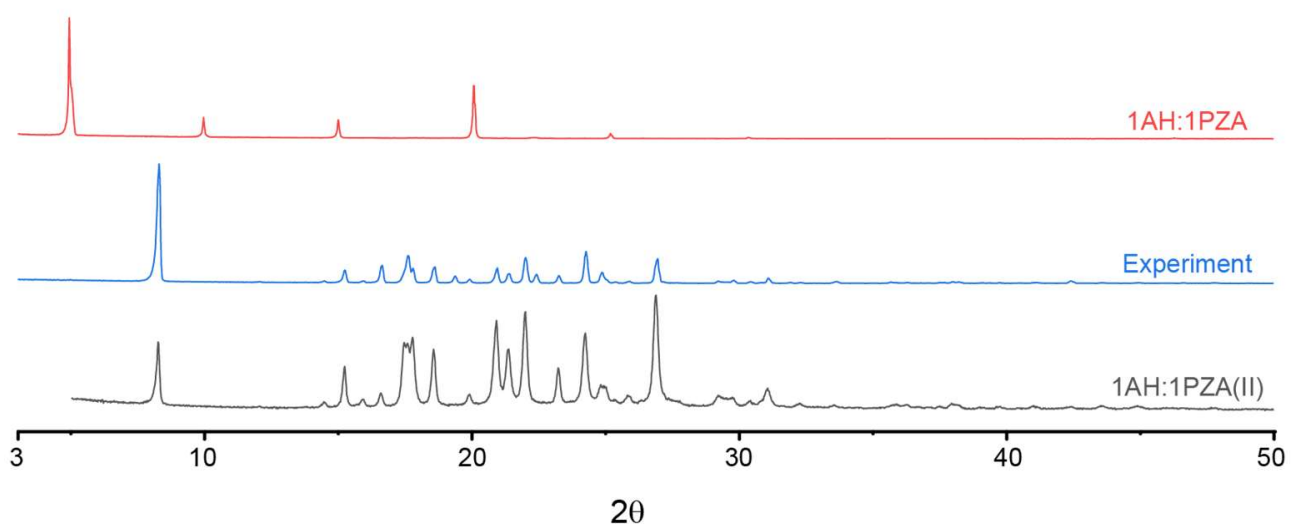

Figure S16. PXRD diffractograms of 1AH:1PZA, the results of a DSC experiment where 1AH:1PZA was heated $1{ }^{\circ} \mathrm{C} / \mathrm{min} . \rightarrow 130{ }^{\circ} \mathrm{C}$ from ambient, and 1AH:1PZA(II).

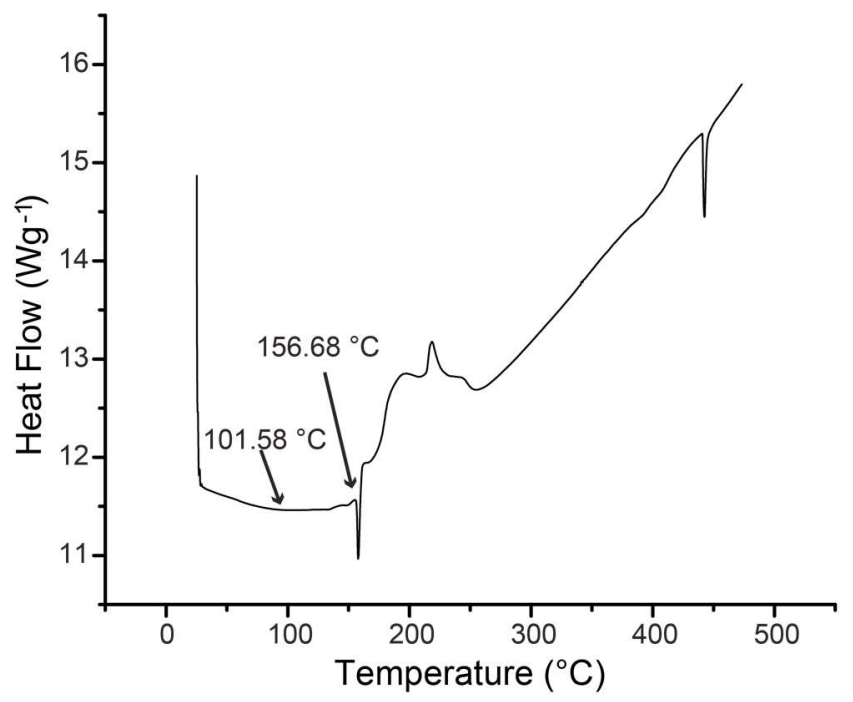

Figure S17. DSC thermogram of 3AH:2PZA 

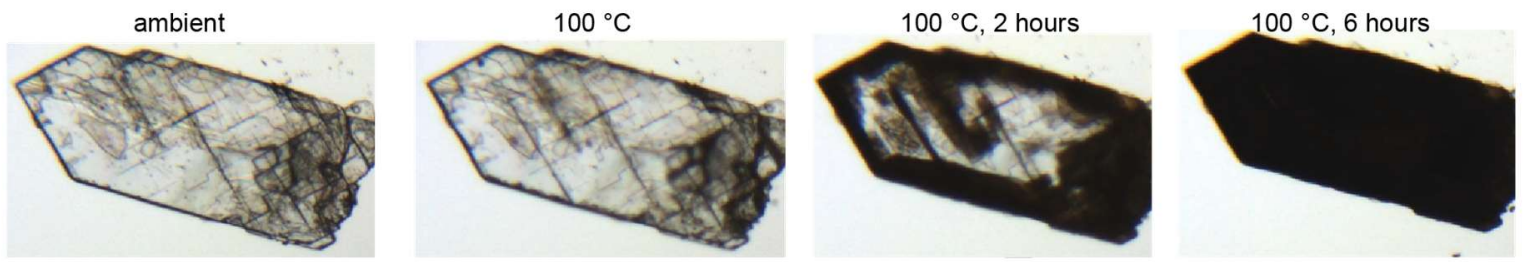

Figure S18. Hot stage microscopy images of 3AH:2PZA. $1^{\circ} \mathrm{C} / \mathrm{min} . \rightarrow 100^{\circ} \mathrm{C}$ from ambient, 6 hour hold.

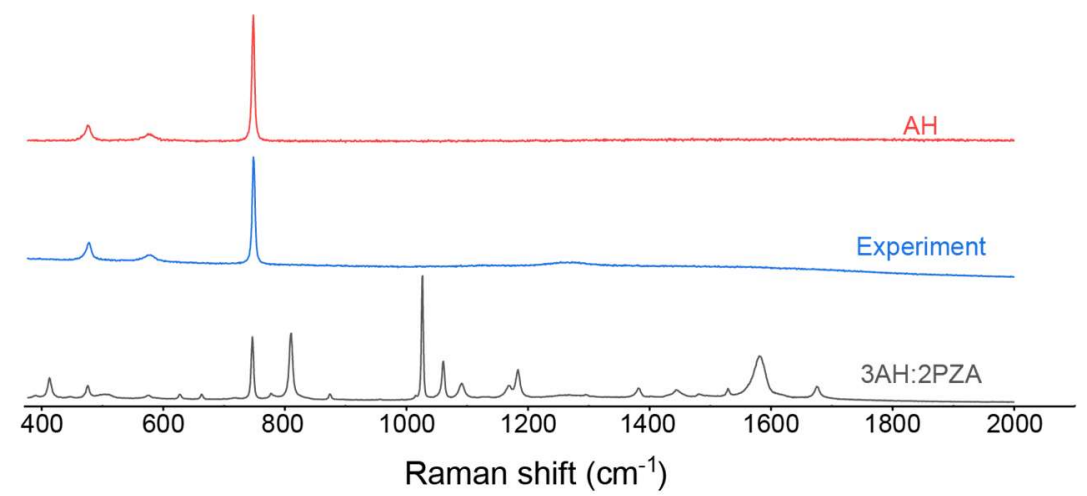

Figure S19. Raman spectra of 3AH:2PZA, the results of a hot stage experiment where 3AH:2PZA was heated $1{ }^{\circ} \mathrm{C} / \mathrm{min} . \rightarrow 100^{\circ} \mathrm{C}$ from ambient and held 6 hours, and AH. This phase change occurs without crystallization of PZA as it leaves the structure as shown in Figure S18.

\section{SI 7. Dynamic Vapor Sorption}

Table S3. Stability of AH-PZA cocrystals as a function of relative humidity $(\mathrm{RH}) ; \mathbf{n}=\mathbf{3}$, $25{ }^{\circ} \mathrm{C}$.

\begin{tabular}{ccc} 
material & RH(\%) & error $(\mathbf{\pm} \%)$ \\
\hline PZA & N/A & N/A \\
AH & 85.08 & 0.26 \\
1AH:1PZA(II) & 81.22 & 0.11 \\
1AH:3PZA & 89.93 & 0.40 \\
1AH:1PZA & 80.81 & 0.58 \\
3AH:2PZA & 79.02 & 1.2
\end{tabular}




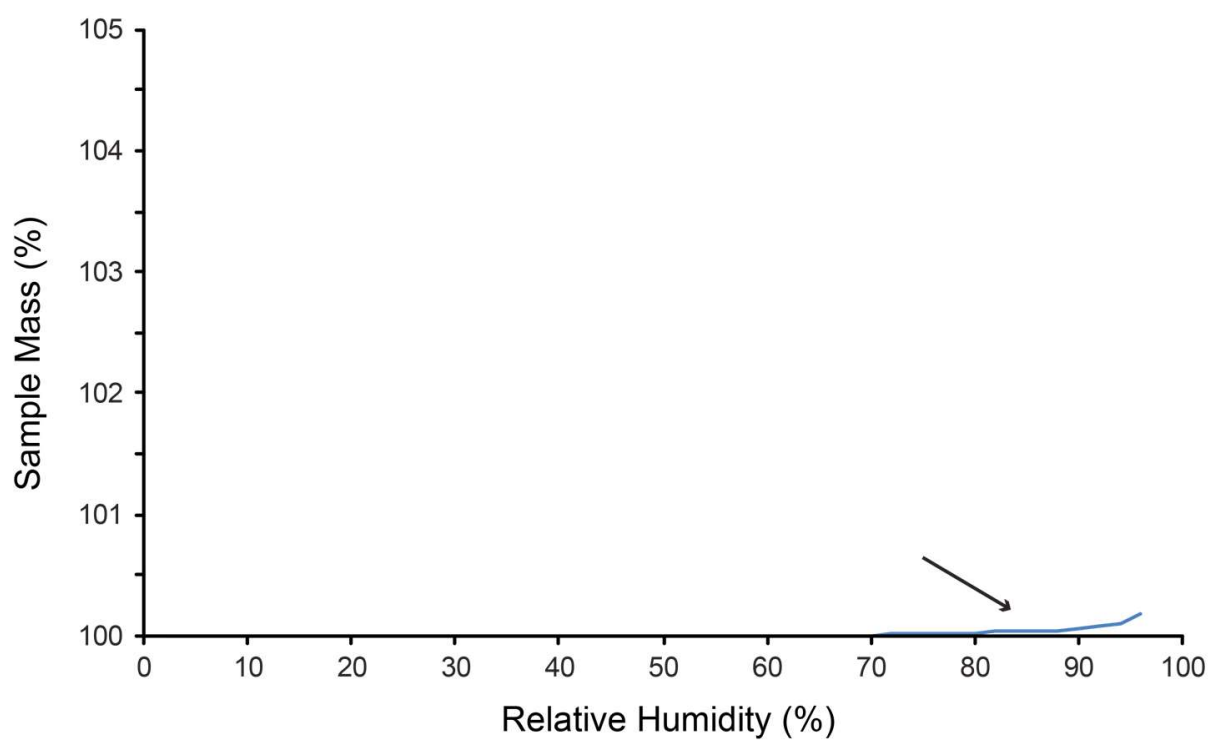

Figure S20. DVS isotherm for PZA

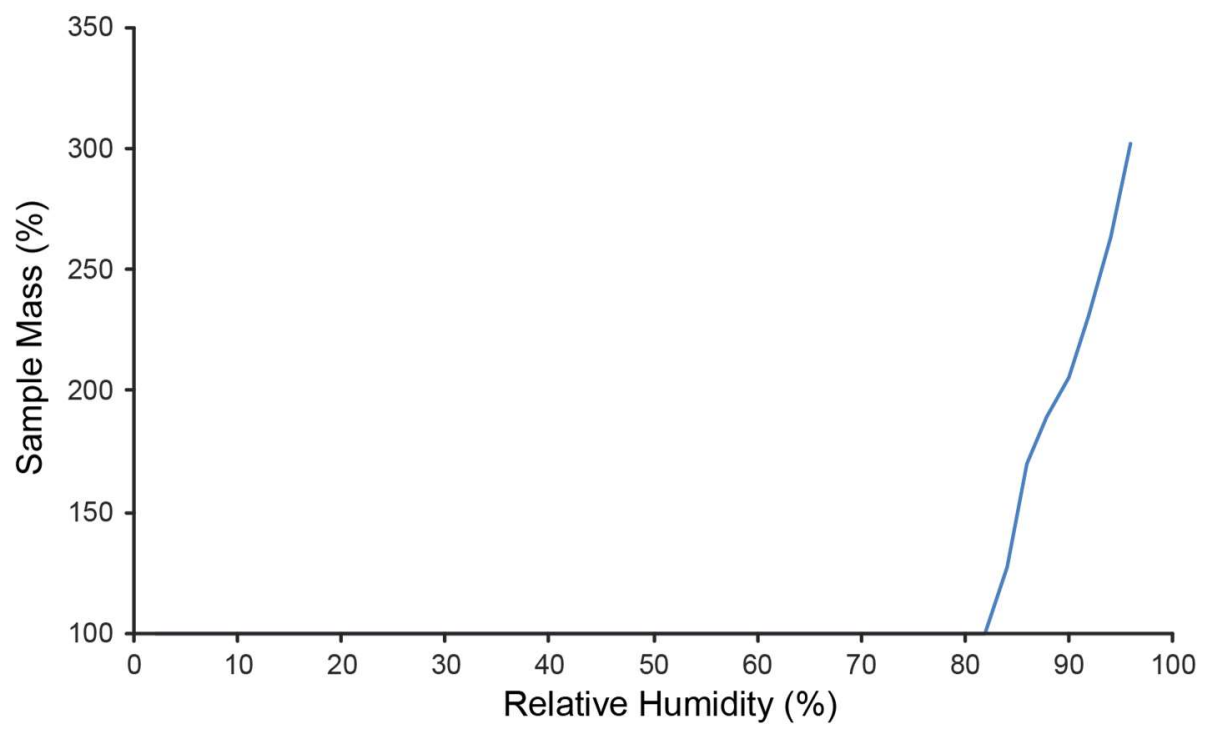

Figure S21. DVS isotherm for $\mathrm{AH}$ 


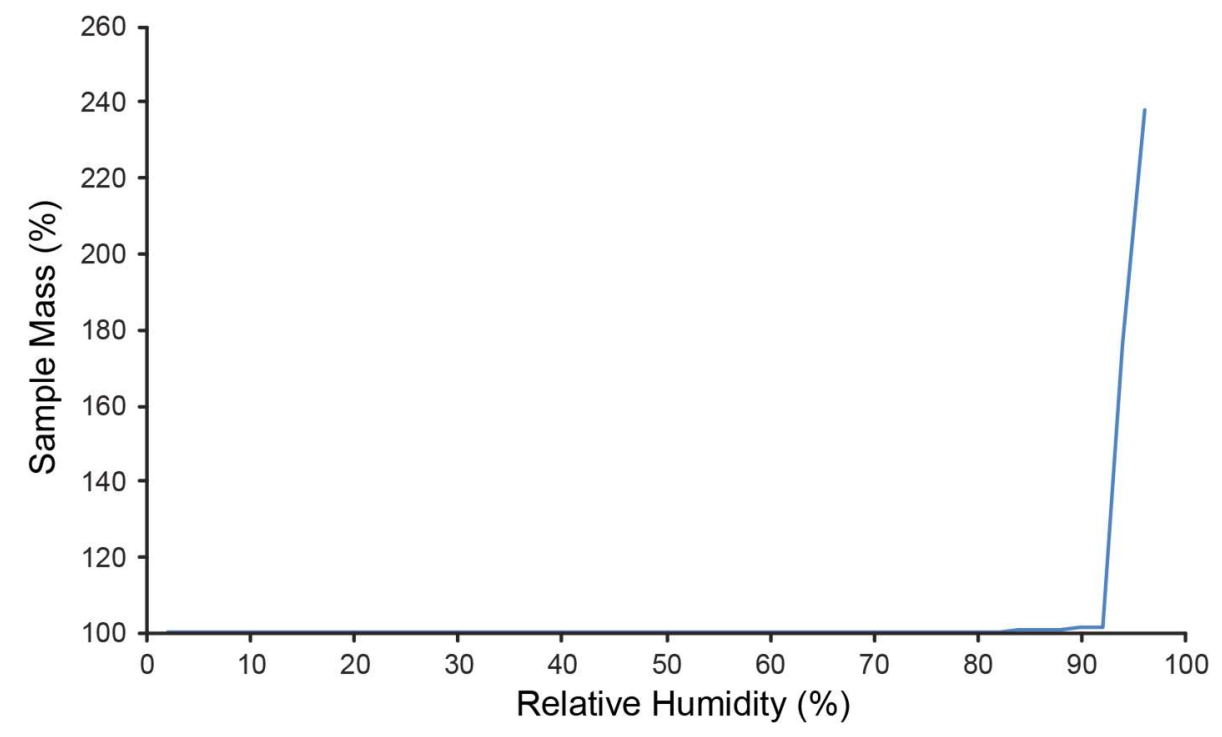

Figure S22. DVS isotherm for 1AH:PZA(II)

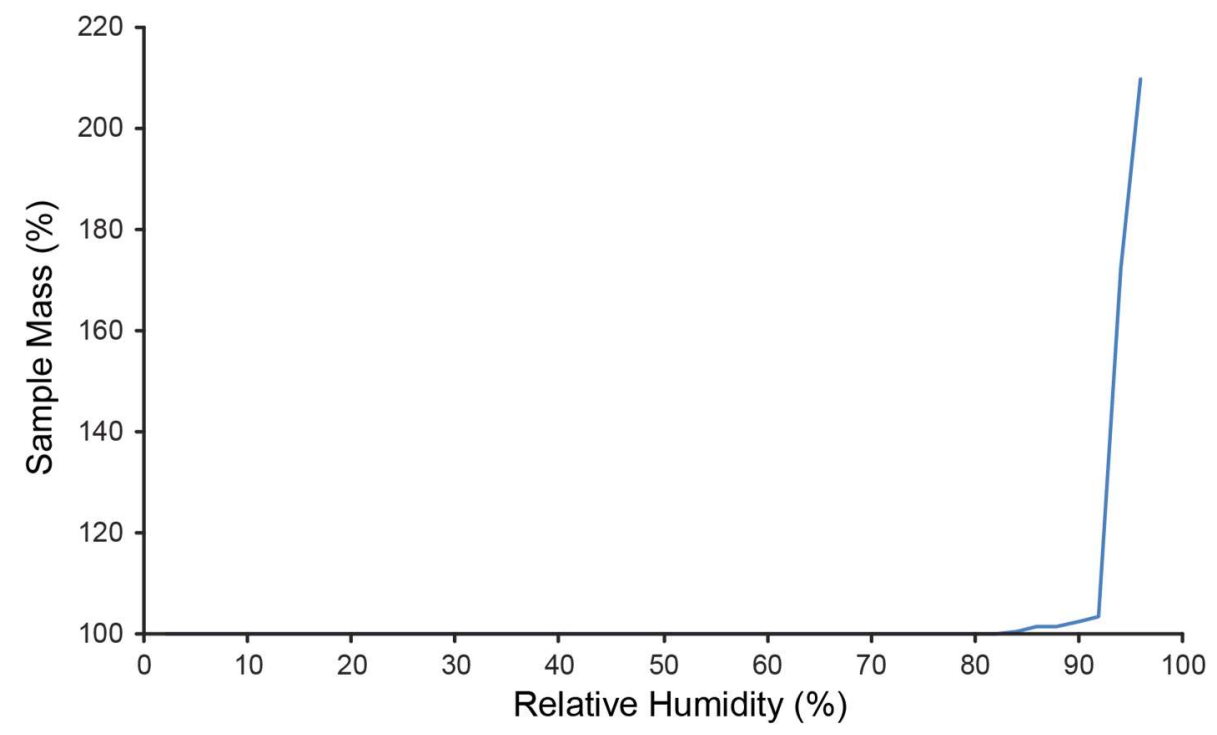

Figure S23. DVS isotherm for 1AH:3PZA 


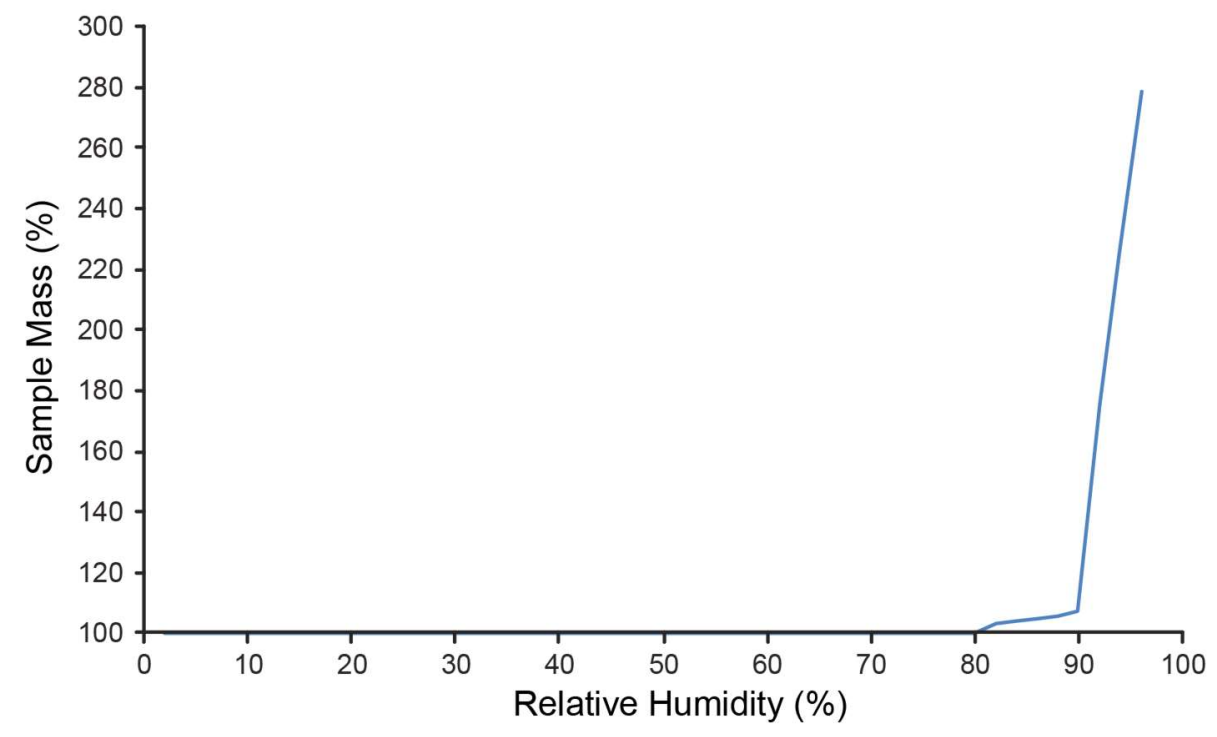

Figure S24. DVS isotherm for 1AH:1 PZA

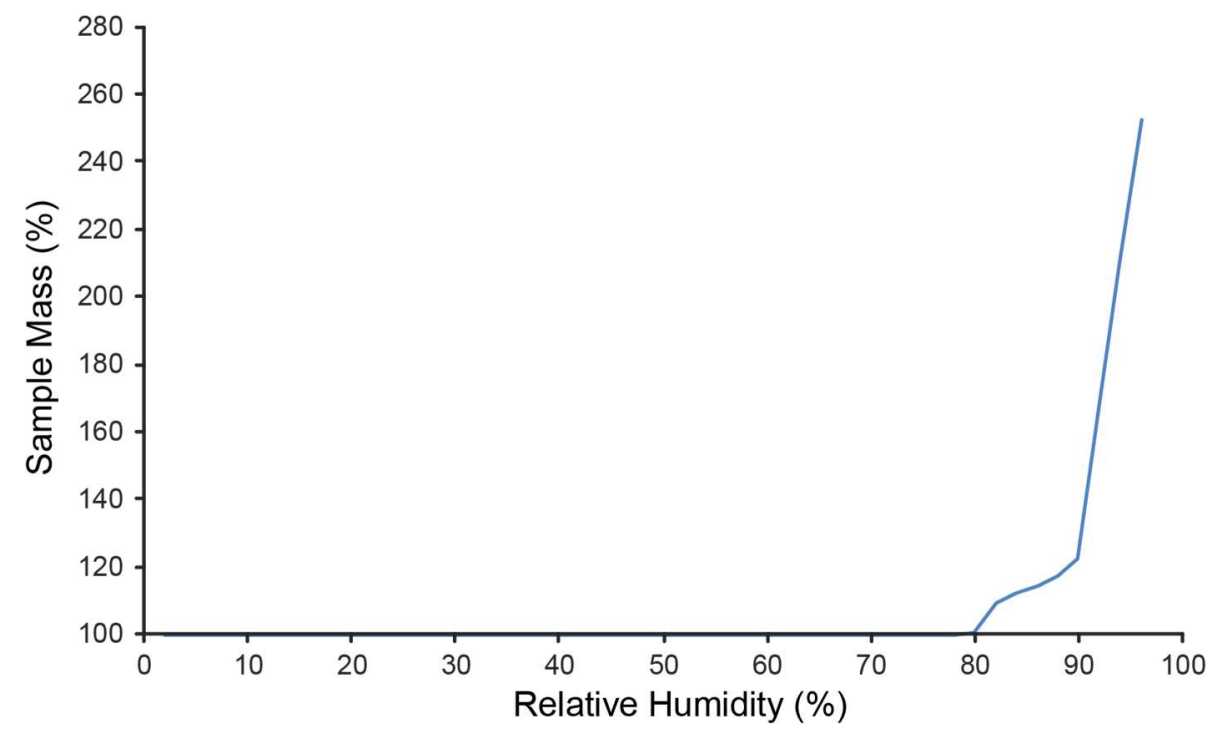

Figure S25. DVS isotherm for 3AH:2PZA 


\section{SI 8. Controlled Humidity Cell Microscopy}

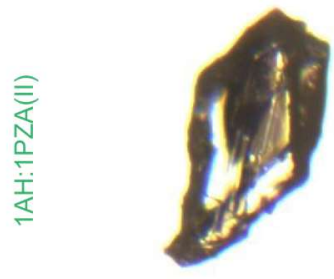

$\mathrm{RH}=18.6 \%$

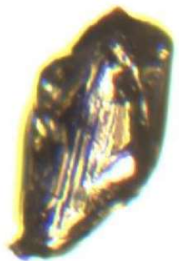

$\mathrm{RH}=79.0 \%$

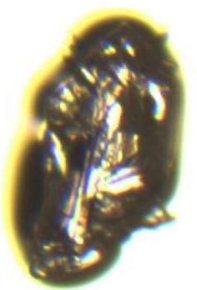

$\mathrm{RH}=80.7 \%$

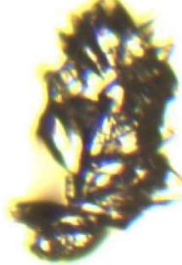

$\mathrm{RH}=81.9 \%$

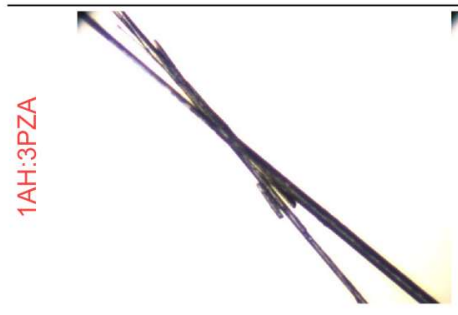

$\mathrm{RH}=42.3 \%$

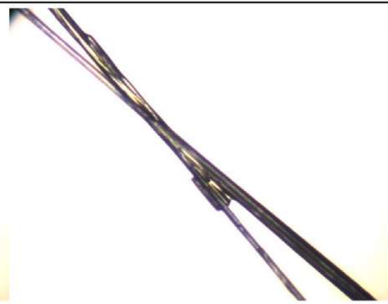

$\mathrm{RH}=87.7 \%$

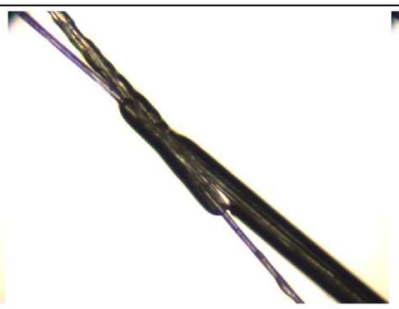

$\mathrm{RH}=90.3 \%$

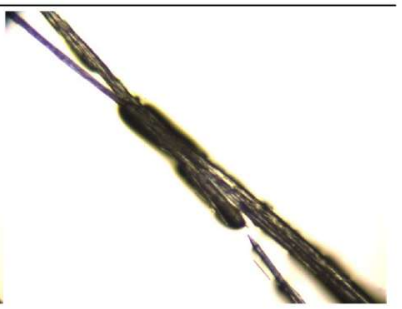

$\mathrm{RH}=90.1 \%$

Figure S26. Images from Controlled Humidity Cell Microscopy experiments on 1AH:1PZA(II) and 1AH:3PZA (upper panels and lower panels respectively).

\section{SI 9. Morphology}
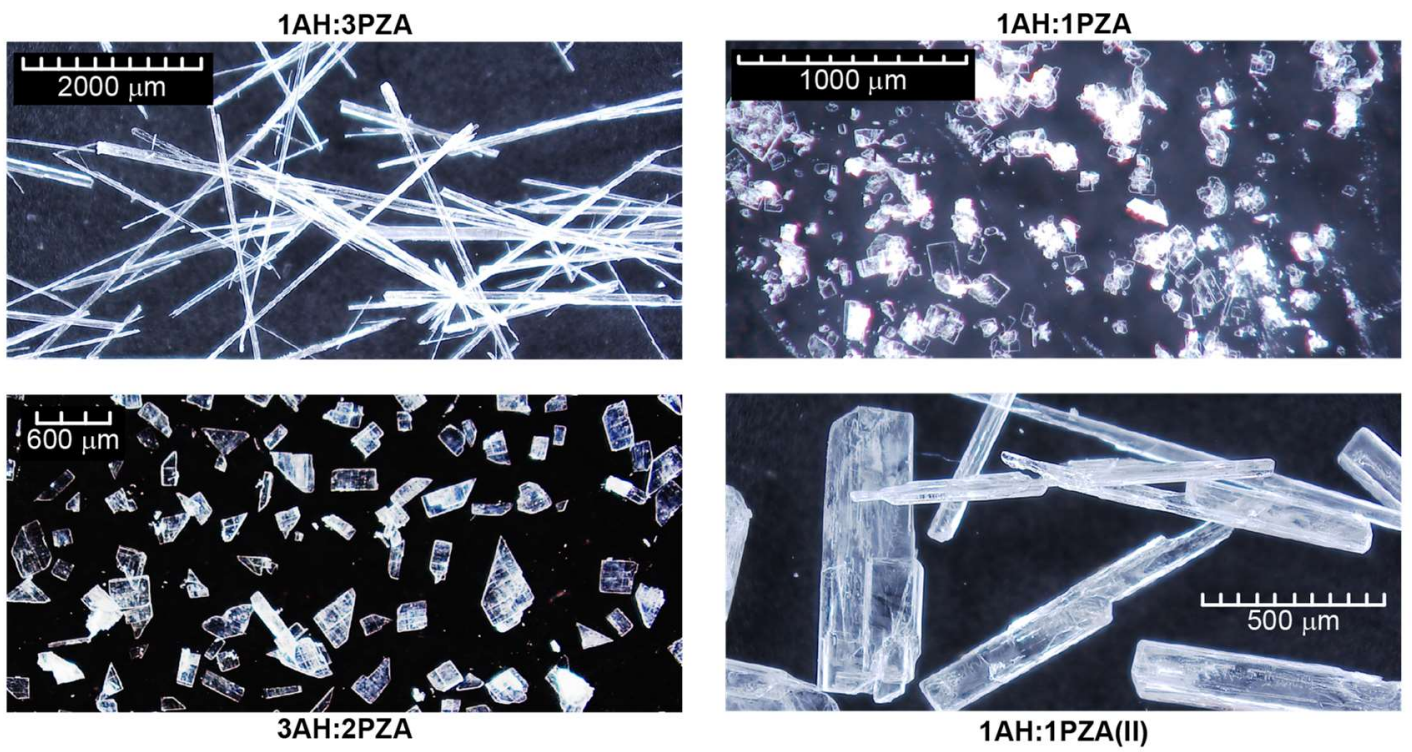

Figure S27. Pictures of crystal populations demonstrating the morphology of the AH-PZA cocrystals. Top left is $\mathbf{1 A H : 3 P Z A}$, top right is $\mathbf{1 A H : 1 P Z A}$, bottom left is $3 \mathbf{A H : 2 P Z A}$, and bottom right is 1AH:1PZA(II). 


\section{SI 10. CSD search}

Search conducted using ConQuest.2020.1 ${ }^{[4]}$ on June, 3, 2020.

For this search a strict definition of "cocrystal" was adhered to- cocrystal is comprised of components which are solid at ambient. This omits solvates/hydrates, cocrystal solvates/hydrates, clathrates, and ionic liquids. Verification of the physical state of the individual components was achieved using common search engines when possible. Components with a melting point at ambient were omitted- ambient taken to be $25^{\circ} \mathrm{C}$. The main search was conducted with the following requirements:

Must include $\mathrm{X}^{+ \text {any }}$ and $\mathrm{X}^{\text {-any }}$, where $+/$-any indicate charged species and " $\mathrm{X}$ " indicates any atom. Must include number of chemical residues $\geq 3$.

Additionally, the ConQuest function to restrict results to the best " $R$ " value was applied. This constraint is designed to exclude multiple determinations of the same structure, either at varied temperature or as better data became available, from the results.

Additional searches were then conducted for common solvents including (as well as deuterated versions): $\mathrm{H}_{2} \mathrm{O}, \mathrm{MeOH}$, acetonitrile, dimethylformamide, $\mathrm{EtOH}$, dichloromethane, chloroform, dimethylacetamide, acetone, dimethylsulfoxide, 1-propanol, acetamide, phosphoric acid, ether, i$\mathrm{PrOH}$, tetrahydrofuran, ethyl acetate, benzene, toluene, and 1,4-dioxane.

The main search was then curated using the manage hitlist function within ConQuest iteratively as follows:

Structures in "main search" but not in "Search X," where search X is one of the separate solvent searches listed above. This creates a new hitlist ("hitlist A") which omits all structures containing the solvent described in search X.

This process was repeated with the newly generated hitlists until a data set was achieved in which all structures including any of the above solvents have been omitted. The resulting data set was then inspected to identify and omit structures containing less common solvents, salt mixture structures (no net-neutral molecular component), or structures that otherwise deviate from the adapted definition of cocrystal provided above.

\section{SI 11. Computations}

Electrostatic potential maps were calculated using B3LYP//6-31+G** as implemented in Spartan 16. 


\section{SI 12. References}

[1] Dolomanov, O. V., Bourhis, L. J., Gildea, R. J., Howard, J. A. K. \& Puschmann, H. "DSR: Enhanced Modelling and Refinement of Disordered Structures With SHELXLJ." Appl. Cryst., 2015, 42, 339.

[2] Sheldrick, G. M. "SHELXT - Integrated Space-Group and Crystal-Structure Determination." Acta Cryst. 2015, A71, 3.

[3] Sheldrick, G. M. "SHELXT - Integrated Space-Group and Crystal-Structure Determination." Acta Cryst. 2015, C71, 3.

[4] Bruno, I. J., Cole, J. C., Edgington, P. R., Kessler, M., Macrae, C. F., McCabe, P., Pearson, J. \& Taylor, R., "New software for searching the Cambridge Structural Database and visualizing crystal structures" Acta Cryst., 2002, B58, 389. 